\title{
Streptomyces turgidiscabies Possesses a Functional Cytokinin Biosynthetic Pathway and Produces Leafy Galls
}

\author{
Madhumita V. Joshi and Rosemary Loria \\ Department of Plant Pathology, Cornell University, Ithaca, NY 14850, U.S.A.
}

Submitted 25 December 2006. Accepted 5 March 2007.

\begin{abstract}
Streptomyces turgidiscabies, a cause of potato scab, possesses a mobilizable pathogenicity island containing multiple virulence genes and a cytokinin biosynthetic pathway. These biosynthetic genes are homologous and collinear with the fas operon in Rhodococcus fascians. Reverse-transcriptase polymerase chain reaction of $S$. turgidiscabies demonstrated that all six genes were transcribed in oat bran broth with and without glucose, though transcription was partially repressed by glucose. The supernatant of $S$. turgidiscabies cultures had cytokinin activity in callus initiation and differentiation assays. Arabidopsis and tobacco plants inoculated with a thaxtomin-deficient mutant $(\Delta n o s)$ produced leafy galls, indistinguishable from those produced by $\boldsymbol{R}$. fascians. Deletion of the ipt gene in the pathway eliminated gall phenotype. Other symptoms on tobacco included production of hairy roots and de novo meristems.
\end{abstract}

Additional keywords: cytokinin biosynthesis.

Of the hundreds of Streptomyces spp. that have been described, relatively few cause plant disease. In fact, this genus is best known for its ability to produce valuable secondary metabolites, including antibiotic, anti-tumor, and nematicidal compounds. Because these filamentous, gram-positive bacteria have a complex life cycle, members of this genus are genetic models for prokaryote development. Potato scab is the most economically important plant disease caused by Streptomyces spp., though species that cause this disease are neither host nor tissue specific (Loria et al. 1997). Of the species known to cause potato scab, Streptomyces scabies (syn. S. scabiei) was the first described and appears to be the most ancient of those characterized (Lambert and Loria 1989). It has a global distribution, presumably due to vegetative propagation of the potato crop, and has been the subject of most of the disease control research over the past 100 years. However, new pathogenic species repeatedly have emerged in agricultural systems and this phenomenon has led to the hypothesis that the genetic determinants for plant pathogenesis are being shared among Streptomyces spp. that are adapted to specific ecological niches. This hypothesis is supported by data showing conservation of virulence genes and associated insertion elements (IS) in multiple strains of phylogenetically diverse pathogenic species (Bukhalid et al. 1998; Healy et al. 1999, 2000).

$S$. turgidiscabies emerged as a virulent pathogen in Japan within the last 50 years (Miyajima et al. 1998; Takeuchi et al. 1996). This species was characterized based on isolates col-

Corresponding author: R. Loria; E-mail: RL21@ @ cornell.edu lected from potato scab lesions with a distinctly erumpent phenotype. The 21 isolates used for characterization were almost identical based on morphological and physiological characteristics, suggesting that the pathogenic strains in the S. turgidiscabies population are clonal. Genetic analysis confirmed the homogeneity of the population. Population studies showed that this new, clonal, pathogenic species occurred in the eastern portion of the island of Hokkaido, whereas a genetically diverse population of S. scabies occurred on the western portion of the island (Takeuchi et al. 1996). These data suggested that S. turgidiscabies might have emerged as the result of horizontal transfer of virulence genes from the more ancient species $S$. scabies.

Discovery of a mobile pathogenicity island (PAI) in the emergent pathogen $S$. turgidiscabies demonstrated that PAIs exist in gram-positive plant pathogens and provided a likely mechanism for the emergence of new pathogenic species in the genus Streptomyces (Kers et al. 2005). Multiple virulence genes reside on a contiguous 660-kb mobilizable fragment in S. turgidiscabies (Kers et al. 2005). Virulence genes on this fragment are conserved in $S$. acidiscabies and $S$. scabies, including the necl gene and the biosynthetic pathway for the nitrated dipeptide phytotoxin, thaxtomin (Bukhalid et al. 1998; Healy and Lambert 1991; Healy et al. 2000; Kers et al. 2004; King et al. 1989). These two loci lie approximately $325 \mathrm{~kb}$ apart and the mobilized fragment has open reading frames (ORFs) with variable $\mathrm{G}+\mathrm{C}$ content and representatives of multiple IS families (Kers et al. 2005).

Interestingly, a plant fasciation (fas) operon, homologous to the six-gene fas operon in Rhodococcus fascians, lies adjacent to the thaxtomin biosynthetic pathway in $S$. turgidiscabies (Kers et al. 2005). The fas operon is absent from S. scabies and $S$. acidiscabies, suggesting that this operon was introduced to the $S$. turgidiscabies PAI after it was acquired from $S$. scabies. Five of the six fas genes are collinear in these two pathogens; fas6 appears to have undergone a rearrangement on the $S$. turgidiscabies chromosome. $R$. fascians is a gall-producing, gram-positive, plant-pathogenic bacterium. Though primarily studied as a model system for molecular plant-microbe interactions (Goethals et al. 2001), R. fascians has emerged as a pathogen on ornamental plants in the United States (M. Putnam, personal communication). Leafy galls that develop on stems and shoots of monocot and dicot stock plants following propagation can result in total loss of affected cultivars. The structure of the cytokinins produced by $R$. fascians has not been determined, but the fas operon is required for pathogenicity (Eason et al. 1996).

Cytokinin biosynthesis is a virulence determinant in other gall-producing bacteria, such as Erwinia herbicola pv. gypsophilae (Lichter et al. 1995), Pseudomonas syringae pv. sa- 
vastanoi (Macdonald et al. 1986), and Agrobacterium tumefaciens (Sakakibara et al. 2005). Like $R$. fascians, these bacteria possess genes that encode an isopentenyltransferase (ipt), an enzyme, which catalyzes the first dedicated step in cytokinin biosynthesis. However, none possess the other genes in the fas operon. In fact, until the fas operon was discovered in $S$. turgidiscabies (Kers et al. 2005), it was not known to exist outside of $R$. fascians. Here, we provide data that demonstrate expression of the fas genes and fas-dependent cytokinin production in $S$. turgidiscabies. We also demonstrate that $S$. turgidiscabies produces leafy galls on tobacco and Arabidopsis and de novo meristem production on tobacco, in a manner indistinguishable from $R$. fascians (de O. Manes et al. 2001, 2004; Vereecke et al. 2000).

\section{RESULTS}

\section{Bioinformatic analysis of the fas operon}

in S. turgidiscabies.

Five of the six S. turgidiscabies genes, fas 1 to 5, are colinear with the six-gene fas operon of $R$. fascians (Fig. 1). These genes overlap or are separated by small intergenic regions, suggesting that they constitute an operon, as they do in $R$. fascians. Upstream of fas 1 in S. turgidiscabies, we discovered two methyltransferase genes ( $m t r l$ and $m t r 2$ ). A role for these genes in cytokinin biosynthesis has not been demonstrated in $R$. fascians. A transmembrane transporter homolog, which is not conserved in $R$. fascians, and fas6 lie directly upstream of $m t r 2$. Interestingly, the fas region is bordered by two IS110 family transposable elements in S. turgidiscabies.

The six $S$. turgidiscabies fas genes are highly similar (67 to $84 \%$ ) to their cognate $R$. fascians homologs (Table 1). The fas 1 gene is homologous to P450 cytochromes (Table 1), which play a critical role in biosynthetic and biodegradative reactions in actinomycetes. Both the $R$. fascians fas 1 (Crespi et al. 1994) and the $S$. turgidiscabies fasl contain the heme-binding loop and conserved cystine residue typical of these enzymes. The fas 2 gene encodes a ferredoxin-pyruvate decarboxylase $\alpha$ subunit homolog and fas 3 encodes a pyruvate decarboxylase $\beta$ subunit homolog. These proteins are likely to be responsible for the oxidation of pyruvate as demonstrated in $R$. fascians (Goethals et. al. 2001). The fas 4 gene encodes an isopentenyl transferase (ipt) that catalyzes the first dedicated step in cytokinin biosynthesis. An amino acid sequence alignment revealed that $S$. turgidiscabies ipt shares the consensus pattern GxTxxGK [ST]xxxxx [VLI] $x x x x x x[\mathrm{VLI}][\mathrm{VLI}] \times x D x \times Q x\{57,60\}[\mathrm{VLI}][\mathrm{VII}] \mathrm{xGG}[\mathrm{ST}]$ predicted by Kakimoto (2001) for all kind of isopentenyltransferases. In this consensus pattern, " $x$ " denotes any amino acid residue, "[ ]" any one of the amino acid residues in these brackets, and " $\{m, n\} " m$ to $n$ amino acid residues. The ATP/GTP binding motif GxxxxGK[TS] is conserved at the amino terminal region of the Streptomyces ipt (Fig. 2). The fas 5 gene is homologous to cytokinin oxidases in plants, including Arabidopsis thaliana, that are involved in cytokinin degradation. The fas 6 gene encodes a lysine decarboxylase homolog and contains the conserved motif (PGGXGTXXE) found in this protein family (Jeon et al. 2006). This gene functions as a virulence determinant in $R$. fascians (Goethals et al. 2001).

\section{The $S$. turgidiscabies fas genes are expressed} and ipt encodes a functional protein.

To determine whether the fas operon is transcribed in $S$. turgidiscabies, we monitored expression of the all of the fas genes using reverse-transcriptase polymerase chain reaction

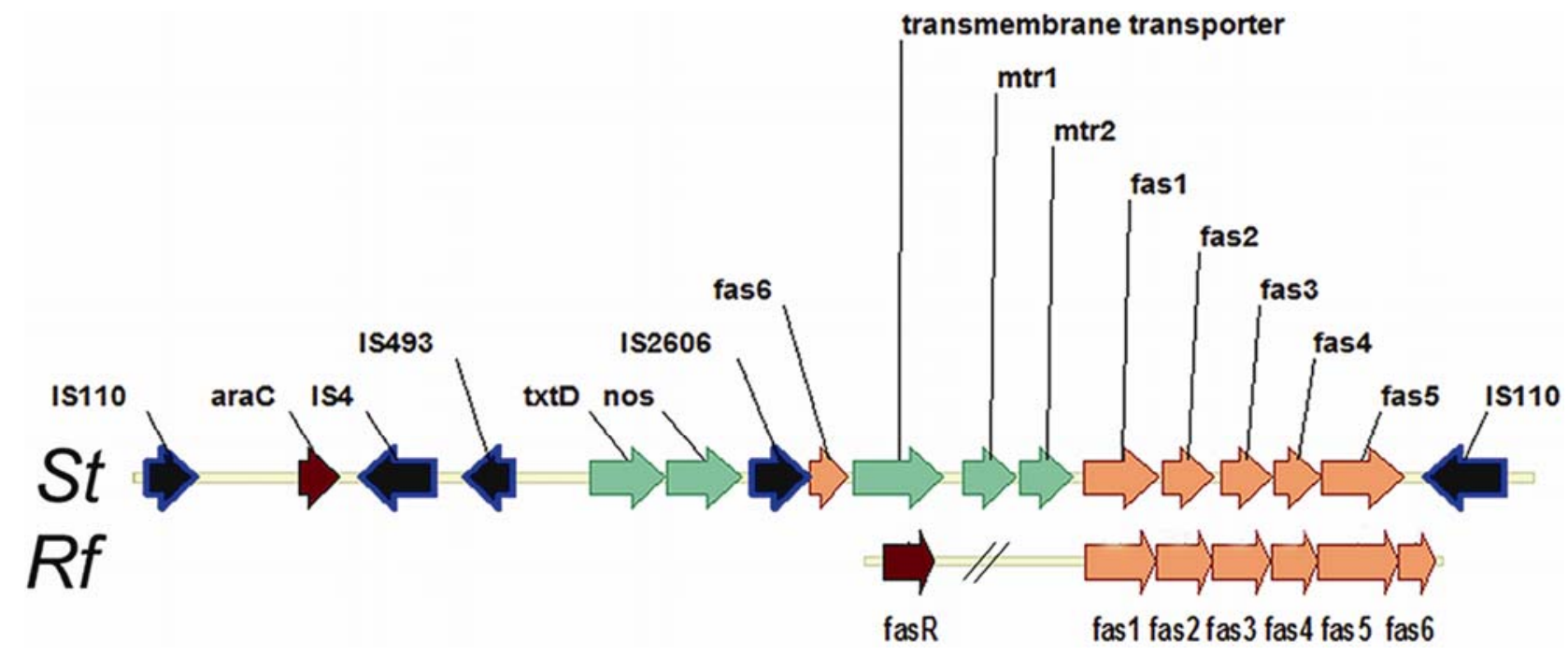

Fig. 1. Genetic organization of the fas loci in Streptomyces turgidiscabies (St) and Rhodococcus fascians (Rf).

Table 1. List of genes present in Fas operon, length, G+C content, similarity and identity to Rhodococcus fascians

\begin{tabular}{|c|c|c|c|c|}
\hline Gene & Length (amino acid) & $\mathrm{G}+\mathrm{C}(\%)$ & Identity (\%) & Similarity $(\%)$ \\
\hline fas 1: Cytochrome $\mathrm{P} 450$ & 400 & 69 & 65 & 77 \\
\hline fas 2: Ferredoxin-pyruvate decarboxylase $\alpha$ & 295 & 66 & 61 & 71 \\
\hline fas 3: Pyruvate decarboxylase $\beta$ & 310 & 66 & 72 & 84 \\
\hline fas 4 : Isopentenyltransferase (cytokinin synthesis) & 257 & 63 & 49 & 68 \\
\hline fas 5: Cytokinin oxidase & 445 & 66 & 54 & 67 \\
\hline fas 6: Lysine decarboxylase & 207 & 67 & 65 & 76 \\
\hline$m t r l:$ Methyltransferase 1 & 284 & 65 & $\ldots$ & $\ldots$ \\
\hline$m t r 2:$ Methyltransferase 2 & 280 & 66 & $\ldots$ & $\ldots$ \\
\hline Transmembrane transporter & 489 & 69 & $\ldots$ & $\ldots$ \\
\hline araC: AraC type transcriptional regulator & 212 & 56 & 31 & 53 \\
\hline
\end{tabular}


(RT-PCR). S. turgidiscabies was grown in oat bran broth (OBB) and OBB amended with $10 \%$ glucose; OBB supports production of the phytotoxin thaxtomin, whereas the addition of glucose represses it. Expression of all of the fas genes (fasl to 6) and two methyl transferase genes (mtrl and 2) was detected in both media (Fig. 3). However, the transcript level was lower in glucose-supplemented OBB than in OBB.

Transcriptional analysis suggested that the fas operon is functional in S. turgidiscabies. To confirm this prediction, we evaluated the ability of the $S$. turgidiscabies IPT protein to complement the osmosensor $\sin 1$ mutant (TM182-CRE) in Saccharomyces cerevisiae (Inoue et al. 2001 ). The SLN1 deleted strain, which carries PTP2-gene under the control of Galinducible promoter and cytokinin receptor CRE1, is conditionally lethal. Viability depends on the presence of galactose or cytokinin in the growth medium (Haberer and Kieber 2002). The Streptomyces turgidiscabies ipt was cloned into the highcopy yeast expression vector p423TEF (Mumberg et al. 1995) and transferred to TM182-CRE. Transformed yeast (TM182CRE/IPT) colonies were able to grow on SD medium (SDURA-LEU-HIS) without galactose or cytokinin (Fig. 4). The yeast transformed with the empty vector (TM182CRE/p423TEF) was able to grow only on SD+Gal-URA-LEUHIS medium (with galactose), confirming the functionality of the $S$. turgidiscabies IPT, whereas original yeast strain TM182CRE was unable to grow without histidine in the media.

\section{S. turgidiscabies produces a cytokinin.}

Because the structure of the cytokinin produced by $R$. fascians is not known, we determined whether $S$. turgidiscabies culture supernatants have cytokinin activity using a callus initiation bioassay. Root segments of the Arabidopsis (ecotype Landsberg) wild type (WT) and the cytokinin-sensitive mutants $c k h 1$ and $c k h 2$ (Kubo and Kakimoto 2000) were grown on tissue culture medium supplemented with kinetin or $S$. turgidiscabies culture supernatants. The synthetic cytokinin, ki-

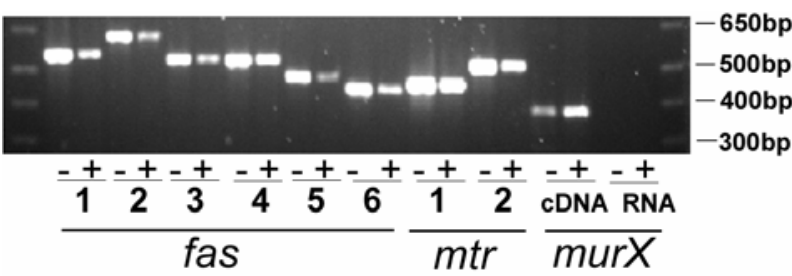

Fig. 3. Expression of the fas genes (fas1-6) and the methyltransferase genes (mtrl-2), based on reverse-transcriptase polymerase chain reaction analysis. The cDNA were synthesized from RNA extracted from Streptomyces turgidiscabies grown in oat bran broth medium with $(+)$ or without (-) glucose. Expression of murx was monitored as a control for cDNA transcription and RNA quality.

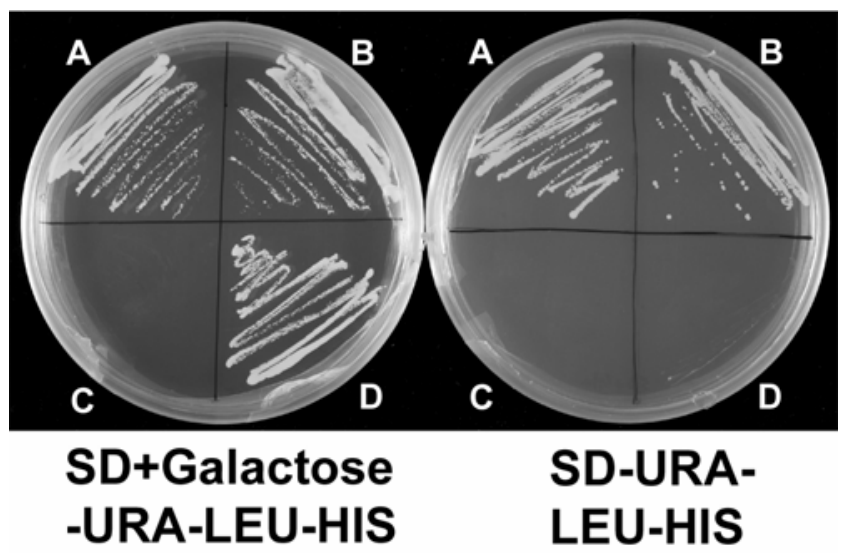

Fig. 4. Complementation of the osmosensor Sln1 yeast mutant (TM182CRE) by the Streptomyces turgidiscabies ipt gene. A and B, Independent transformant (TM182-CRE/IPT) yeast clones carrying ipt gene growing on SD-URA-LEU-HIS medium with or without galactose. C, Original yeast strain TM182-CRE was unable to grow without histidine in the media. D, Yeast clone carrying empty vector p423TEF grows in absence of histidine but only in presence of galactose (plate on left).

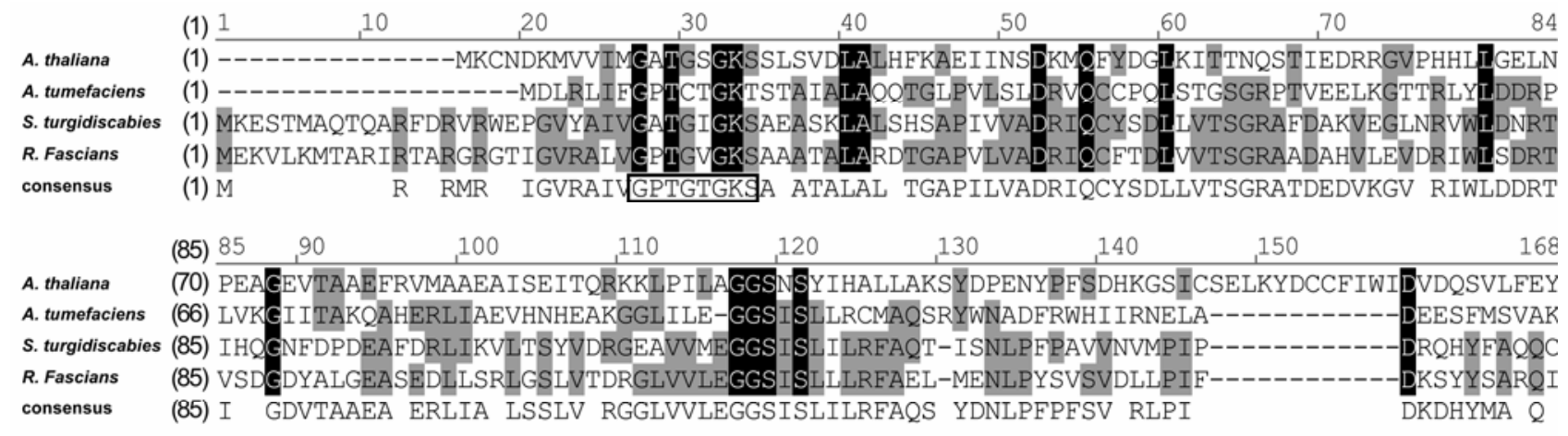

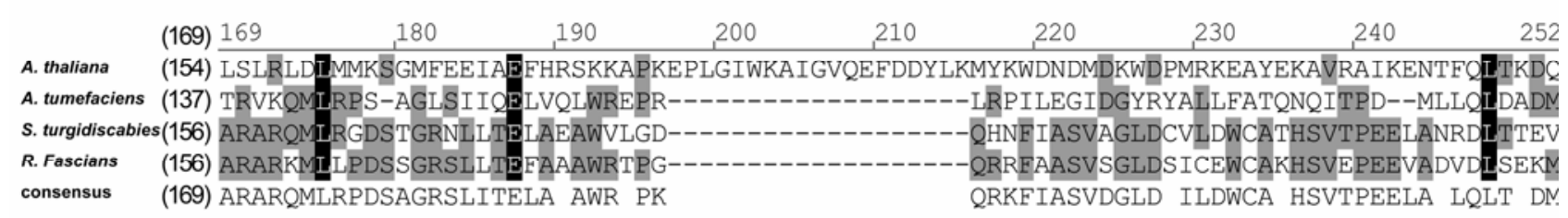

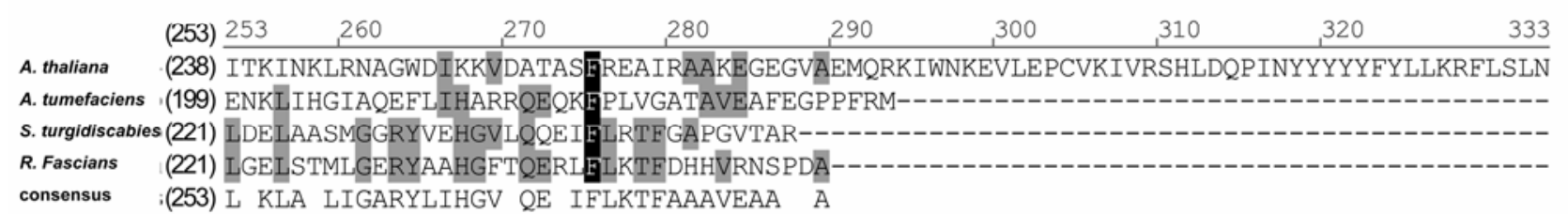

Fig. 2. Alignment of the amino acid sequence of Fas4 (IPT) from Streptomyces turgidiscabies with the IPT sequences in Arabidopsis thaliana, Rhodococcus fascians, and Agrobacterium tumefaciens. A consensus sequence for IPT is provided and the conserved ATP/GTP binding motif GxxxxGK[TS] is boxed. 
netin, induced green calli without formation of root primordial structures in the WT Arabidopsis, as did the cytokinin-sensitive mutants at lower kinetin concentrations. Tissue grown on media supplemented with Streptomyces culture supernatant $(50 \mu \mathrm{l} / \mathrm{ml}$ ) produced rapidly proliferating green calli (Fig. 5). Response of the plant tissue to the supernatant was very similar to kinetin at $100 \mathrm{ng} / \mathrm{ml}$. The mutants $c k h 1$ and $c k h 2$ were more responsive to Kinetin treatments than the WT, as expected. Likewise, these cytokinin mutants responded more strongly to the supernatant from $S$. turgidiscabies cultures. Although root primordia-like structures were produced from callus grown in the presence of kinetin, they were not produced in calli grown in the presence of culture supernatant (Fig. 5). Calli produced from WT Arabidopsis initiated organogenesis when cultured on $S$. turgidiscabies supernatant.

\section{S. turgidiscabies infection causes leafy galls and induces de novo meristems.}

Streptomyces spp. that cause potato scab have never been reported to produce leaf galls or similar symptoms. However, the functionality of the fas genes in S. turgidiscabies suggested that this scab pathogen might have the ability to produce symptoms similar to those produced by $R$. fascians. An $S$. turgidiscabies Anos mutant, which is deficient in thaxtomin production (Kers et al. 2004), was used in plant bioassays to avoid the necrogenic affects of this toxin. Log-phase cultures grown in OBB were used as inoculum. Symptoms produced on plants varied greatly, depending on the plant species, the site of inoculation, and the age of the plant. Infection of germinating tobacco seedlings resulted in hairy, bushy roots with little growth inhibition (Fig. 6A). However, when 2-week-old plants of tobacco were inoculated, multiple buds formed in the shoot meristem region, where bacteria growth was visible (Fig. 6B). Inoculation of the axillary meristems of 3-week-old tobacco resulted in the formation of calli or multiple buds (Fig. 6C) at the infected leaf axils within 7 to 10 days. By 4 weeks, these calli developed into gall-like structures with small, thick green

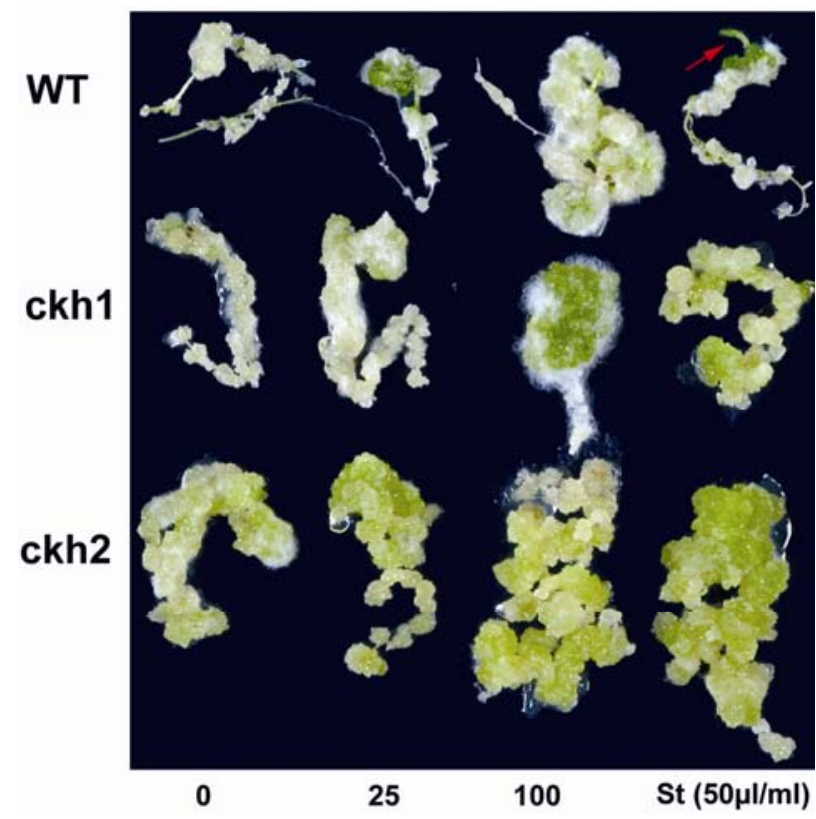

Fig. 5. Callus initiation from Arabidopsis root segments. Root segments of wild-type Landsberg (WT) and two cytokinin-sensitive mutants, ckhl and $c k h 2$, were cultured on Murashige and Skoog agar +2,4-D (200 mg/liter) media containing kinetin $(0,25$, or $100 \mathrm{mg} / \mathrm{liter})$ or Streptomyces turgidiscabies $(\mathrm{St})$ culture supernatant $(50 \mu \mathrm{l} / \mathrm{ml})$. Organogenesis induced in WT callus is indicated by an arrow. leaves (Fig. 6D). Growth of the pathogen was visible in the leaf axils and plant growth was greatly reduced relative to noninoculated plants. When tobacco plants were decapitated to suppress apical dominance, before inoculating the leaf axils, profuse bud proliferation occurred at the site of inoculation (Fig. 6E). Multiple bud formation occurred at inoculated apical meristems with or without decapitation. De novo meristem formation and shoot regeneration occurred on inoculated leaf petioles and stems (Fig. 6F). An S. turgidiscabies $\Delta$ nos $\Delta i p t$ mutant did not produce galls or cause shoot regeneration or de novo meristem production (Fig. 6G). A parallel infection study was carried out with $A$. thaliana (ecotype Columbia); leafy galls were formed at the shoot meristem and both shoot and root growth was greatly reduced relative to noninoculated plants (Fig. 7A and B). Interestingly, infected plants produced larger and more numerous trichomes than did control plants (Fig. 7C and D).

\section{DISCUSSION}

Based on amino acid similarity, $\mathrm{G}+\mathrm{C}$ content, and gene organization, it is clear that the fas genes in $R$. fascians and $S$. turgidiscabies have a common ancestor (Fig. 1; Table 1). The fas genes lie on a mobilizable PAI in S. turgidiscabies (Kers et al. 2005). This PAI is conserved in S. scabies and S. acidiscabies but it lacks the fas operon in these two species. It seems likely that the fas operon was incorporated into the PAI after it was mobilized into $S$. turgidiscabies. The fas genes are bordered by IS110 family transposable elements in $S$. turgidiscabies, suggesting that mobilization may have occurred via a transposition event (Fig. 1). The fas operon resides on a linear plasmid in $R$. fascians and on a mobilizable PAI in S. turgidiscabies, in both cases providing opportunities for mobilization into other bacteria. Interestingly, a gall-producing Streptomyces sp. emerged as an economically important pathogen of cucurbits in Japan within the last 25 years (Yoshida and Kobayashi 1991) and in Costa Rica in the last 10 years (data not presented). Analysis of this emergent pathogen for the presence of the fas operon on a PAI would be a logical next step in understanding the evolution of pathogenicity in the genus Streptomyces.

The fas operon has not been described from bacteria other than $R$. fascians and $S$. turgidiscabies. The existence of this operon in gram-positive bacteria but not in gall-producing gram-negative bacteria, such as E. herbicola pv. gypsophilae, Pseudomonas syringae pv. savastanoi, and Agrobacterium tumefaciens is a matter for speculation. Interestingly, the ipt genes in these bacteria are located on plasmids, suggesting that the genes required to synthesize cytokinins are mobilized frequently. In fact, cytokinin biosynthesis appears to be a trait that is relatively common in plant-associated bacteria. For example, there is evidence for cytokinin production by Frankia sp. (Stevens and Berry 1988), Bacillus subtilis (Arkhipova et al. 2005), and Azotobacter vinelandii (Taller and Wong 1989), indicating that cytokinins can confer a fitness advantage in plant associations. None of these bacteria produce galls, though Frankia and Azotobacter spp. produce nodules.

Transcription of all six of the $S$. turgidiscabies fas genes occurred in OBB and OBB amended with glucose but not in CRM (Pigac and Schrempf 1995), Terrific Broth, or Luria Broth (data not provided). Plant components in OBB are required for transcription of the fas locus, but transcription is not completely repressed in the presence of glucose (Fig. 3). Thaxtomin production also occurs in OBB but is repressed by glucose. In contrast, the production of cytokinin via the fas operon is tightly controlled in $R$. fascians and requires induction by extracts of infected plant tissue; no induction occurs with healthy plant tissue (Temmerman et al. 2000). The att locus, 
which is in the vicinity of the fas operon on the $R$. fascians plasmid pFiD188, is essential for the formation of these inducing factors (Maes et al. 2001). An AraC-type regulatory gene, fas $R$, regulates fas gene expression in $R$. fascians. Deletion mutants of fasR are blocked for fas gene transcription, cytokinin production, and virulence. There is an AraC family regulator on the $S$. turgidiscabies PAI upstream of the fas genes and in the vicinity of the thaxtomin biosynthetic genes. Unlike the fas and $\mathrm{mtr}$ genes, this gene is conserved in S. scabies and $S$. acidiscabies. It is possible that this AraC is involved in regulation of the fas genes in S. turgidiscabies, however, it appears to have been present on the PAI prior to the introgression of the fas operon.

$S$. turgidiscabies produces all of the cytokinin-dependent symptoms produced by $R$. fascians, including leafy galls on tobacco and Arabidopsis that are indistinguishable from those produced by $R$. fascians (de O. Manes et al. 2004; Goethals et al. 2001). Leafy gall production has been studied extensively in $R$. fascians. Dormant axillary meristems become active and generate shoots, but growth of these shoots is inhibited (Vereecke et al. 2000). At the same time, cortical cells in stems and petioles divide to form new shoot primordia (de O. Manes et al. 2001) and cells neighboring the vascular tissue in leaves give rise to de novo formed shoots (Vereecke et al. 2000). The repetition of these processes ultimately leads to the formation of a dense gall of meristematic tissue. No other gall-forming bacteria produce leafy galls, suggesting that the properties or metabolism of the cytokinins produced via the fas operon may be different from those produced $R$. fascians. The fact that $S$. turgidiscabies also produces leafy galls is consistent with this
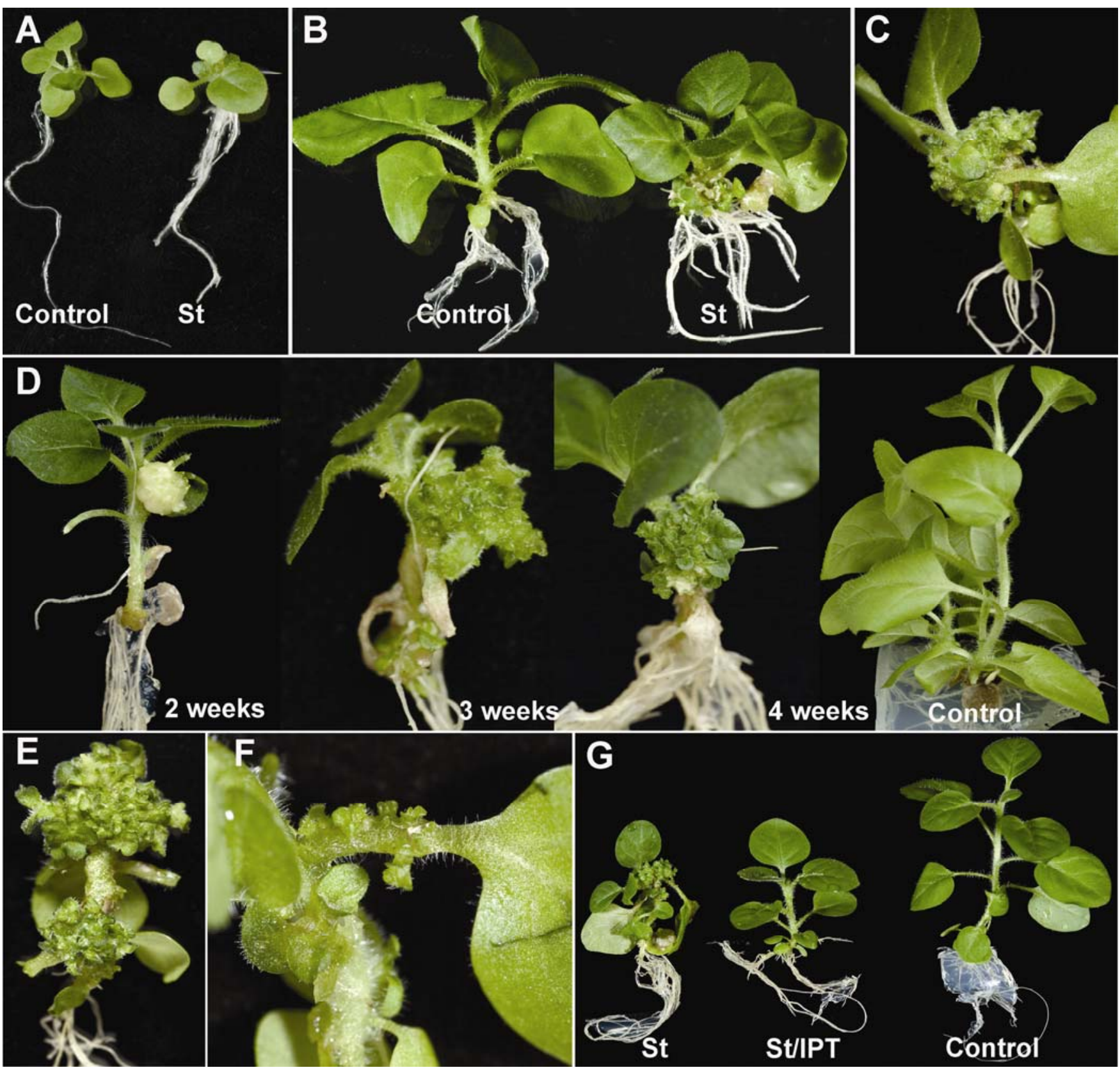

Fig. 6. Symptoms of tobacco infected by the fas operon containing Streptomyces turgidiscabies Anos mutant. A, Tobacco seedlings infected with S. turgidiscabies (Anos) (St) and noninoculated plants (control). B, Multiple buds at the point of infection in the shoot meristem region. C, Leafy gall formation at infected leaf axils. D, Initiation of calli, bud proliferation, and shoot regeneration for over 4 weeks, ultimately resulting in a gall with small, thick green leaves at the point of inoculation, and noninoculated plant (control). E, Multiple buds at inoculated apical meristem. F, De novo meristem formation on inoculated

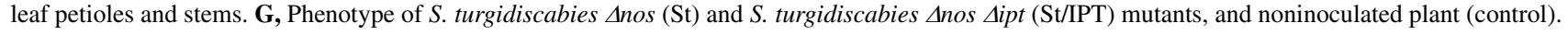


hypothesis. We noticed another plant phenotype that is characteristic of excess cytokinin production; trichomes were abnormally large and numerous on Arabidopsis plants infected with S. turgidiscabies (Greenboim-Wainberg et al. 2005).

In plants, cytokinin works with auxin to regulate many developmental processes, including vascular differentiation, lateral root initiation, shoot and root apical dominance and root gravitropism, and de novo shoot formation (Aloni et al. 2006; Mahonen et al. 2006). Gall production requires both auxin and cytokinin, and gall-producing gram-negative bacteria produce both hormones (Jameson et al. 2000). S. scabies produces indole 3-acetic acid (IAA) (Manulis et al. 1994), though the genetics and regulation of biosynthesis are not known; however, auxin production by $S$. turgidiscabies has not been evaluated. Production of IAA by $R$. fascians recently was documented. Interestingly, production is highly induced by infected-plant extracts (Vandeputte et al. 2005).

Because $S$. turgidiscabies has never been reported to produce galls on plants in nature, what effects might cytokinin biosynthesis have on the interaction of $S$. turgidiscabies and potato? This species originally was isolated from scab lesions on potato. In the original description of $S$. turgidiscabies, it was noted that this species caused larger, more "turgid" lesions than did
S. scabies. It is tempting to speculate that this large, erumpent lesion is due to cytokinin production. Perhaps reproduction of the pathogen is greater in lesions or pathogen dispersal is more effective in these large, erumpent lesions. An increase in cytokinin levels has been correlated with accumulation of metabolites in fungal host-pathogen interactions (Angra-Sharma and Sharma 1999). Walters and McRoberts propose a mechanism by which cytokinin-induced increases in invertase activity occurring early on in the host-pathogen interaction result in nutrient mobilization toward the infection site in biotrophic interactions (Walters and McRoberts 2006). However, the role of cytokinins in this plant-microbe interaction could be multifaceted because cytokinin can act as an apoptotic inducer in plants (Carimi et al. 2003) and act as a signaling molecule for antibiotic production in Streptomyces spp. (Yang et al. 2006).

\section{MATERIALS AND METHODS}

\section{Strains, plasmids, and culture conditions.}

A $\Delta$ nos mutant strain of $S$. turgidiscabies Car8 that produces trace quantities (approximately $3.0 \%$ of WT) of thaxtomin (Kers et al. 2004, 2005) was used in this study to minimize the necrotic phenotype effect of this phytotoxin in plant infection
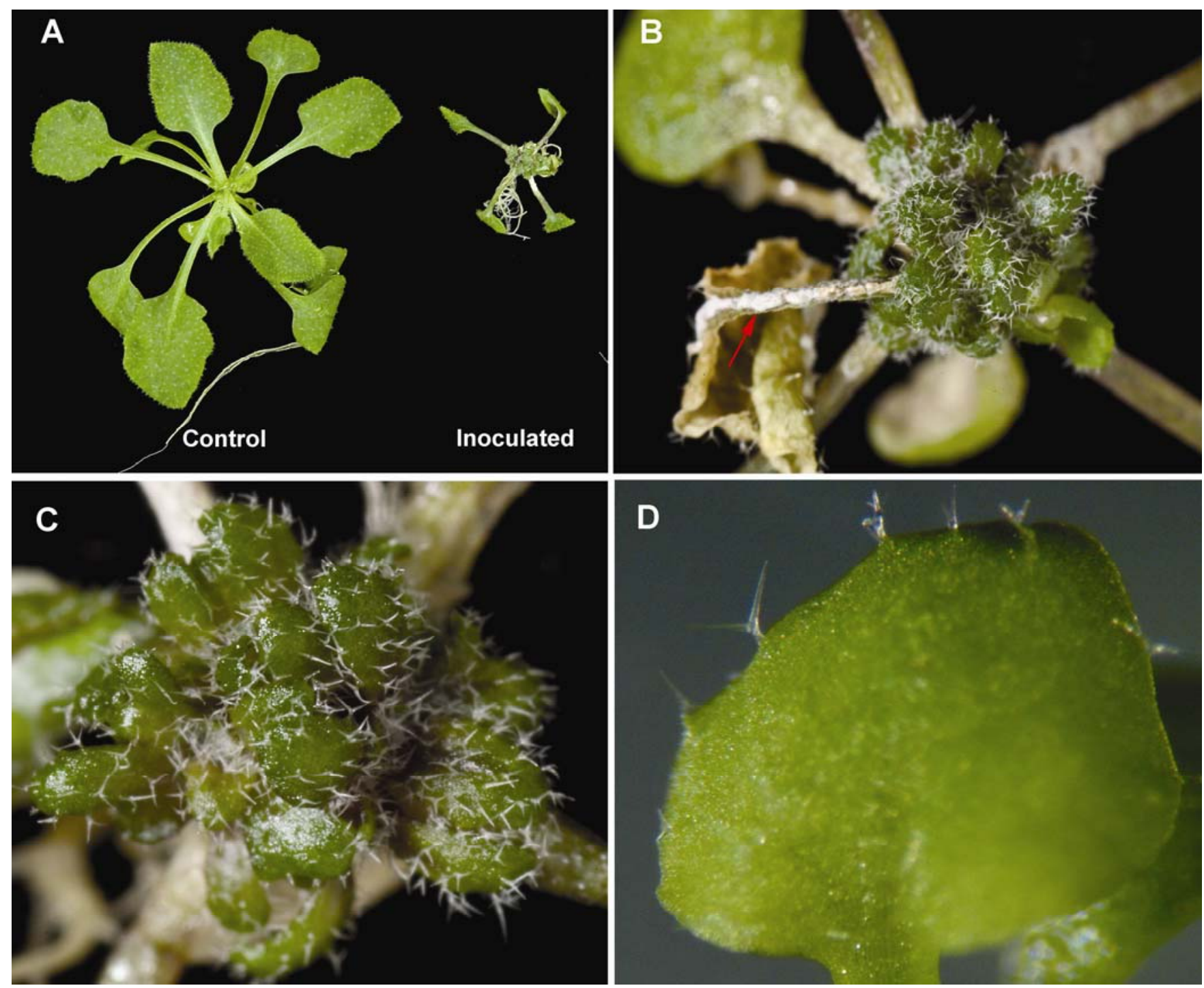

Fig. 7. Symptoms of the fas operon containing Streptomyces turgidiscabies (Anos) on Arabidopsis (ecotype Columbia). A, Inoculated (Anos) and noninoculated (control) plants. B, Small, thick, green leaves form a leafy gall at apical meristem on inoculated plant. Growth of Streptomyces on plant tissue is indicated by arrow. C, Trichome production on inoculated plant. D, Uninoculated control plant. 
studies. S. turgidiscabies strains were grown routinely in the International Streptomyces Project (ISP) medium 2 and ISP medium 4 (BD Biosciences, San Jose, CA, U.S.A.) as described previously (Kers et al. 2004, 2005). Spore suspensions of $S$. turgidiscabies Car8 strains were prepared as described by Kieser and associates (2000). The strains were grown for 2 days in OBB (Goyer et al. 1998) at $28^{\circ} \mathrm{C}$. Mycelium was recovered from cultures by spinning at $150 \mathrm{rpm}$ and used in plant virulence assays. DNA was extracted from Streptomyces cultures grown in CRM medium (Pigac and Schrempf 1995) for 24 to $48 \mathrm{~h}$ at $30^{\circ} \mathrm{C}$ using a modification of the procedure of Rao and associates (1987). For RNA extraction, $10^{5}$ spores were inoculated in OBB or OBB $+10 \%$ glucose media and grown for 4 days at $26^{\circ} \mathrm{C}$. Mycelium growth was not effected by glucose.

\section{Bioinformatic analysis.}

Putative ORFs and protein coding regions were identified by database similarity searching, using BLAST (National Center for Biotechnology Information) as described earlier (Kers et al. 2005). These sequence data have been submitted to the GenBank database (accession numbers AY7079 to AY7083). DNA and protein sequences were mapped and aligned using Vector NTI Suite 8.0 (InforMax, Frederick, MD, U.S.A.).

\section{Disruption of the ipt gene.}

A cosmid library of $S$. turgidiscabies was mutagenized for DNA sequencing as described previously (Kers et al. 2005). A S. turgidiscabies cosmid (Cos891) with a Tn5 kanamycin cassette inserted in the ipt (fas4) gene, 331 bp downstream of start codon, was selected. A 7,835-bp EcoRV fragment of Cos891 containing disrupted fas operon was ligated into the EcoRV site of pOJ260 $\left(\right.$ apra $\left.^{\mathrm{R}}\right)$. Ligated product was transformed to Escherichia coli $\mathrm{DH} 5 \alpha$ and colonies were selected with apramycin. The pOJ260 containing the disrupted fas operon construct then was propagated in E. coli ET12567 containing the helper plasmid pUZ8002 and conjugated to $S$. turgidiscabies. Colonies were selected on kanamycin media.

\section{Yeast strains, growth conditions, and complementation assay.}

Yeast strain TM182 (MAT $\alpha$ leu2 ura3 his3 sln1::hisG+ pSSP25) is deficient in the SLN1 gene, which encodes an osmosensing histidine kinase; this mutation is lethal in media containing glucose. This $\sin 1$ mutant carrying a plasmid containing the $\mathrm{P}_{G A L I}-P T P 2$ promoter fusion gene grows normally in media containing galactose (Maeda et al. 1994). A plasmid (p415CYC-CRE1) carrying a plant cytokinin receptor CRE1 was introduced to the $\sin 1$ mutant (TM182-CRE) and suppressed conditional lethality in the presence of cytokinin in the media (Inoue et al. 2001). This modified strain TM182-CRE can grow in the absence of galactose only when cytokinin is present in the media. For our study, strains TM182 carrying a plasmid p415CYC-CRE1 (TM182-CRE) were kindly supplied by Dr. Tatsuo Kakimoto (Osaka University, Japan). Yeast strains were grown on synthetic dropout (SD) medium $(0.67 \%$ Bacto-yeast nitrogen base and $0.065 \%$-His/-Leu/-Ura DO supplement) (Clontech, Palo Alto, CA, U.S.A.) supplemented with $2 \%$ galactose or glucose for cytokinin assay, where appropriate, with Leu at 30 and His at $20 \mu \mathrm{g} / \mathrm{ml}$. The entire coding region of ipt was PCR amplified and cloned into the yeast expression vector $\mathrm{p} 423 \mathrm{TEF}\left(\mathrm{P}_{T E F 2}\right.$ promoter, $H I S 3^{+}$marker) at the BamH1 and Cla 1 sites, generating p423TEF-IPT (ampR). After sequence confirmation, plasmids were transformed to the yeast strain TM182-CRE by the lithium acetate method (Ausubel et al. 1998). Complementation of the His auxotrophy was used to select for transformants carrying p423TEF vector and p423TEF-IPT constructs. In galactose-supplemented me- dia, the yeast transformant carrying the empty vector (TM182$\mathrm{CRE} / \mathrm{p} 423 \mathrm{TEF}$ ) grows in the absence of histidine, whereas the original yeast strain TM182-CRE was unable to grow without histidine in the media. Yeast clones (TM182-CRE/IPT) carrying the ipt gene grow in medium without galactose and without histidine (SD-URA-LEU-HIS).

\section{RNA extraction and RT-PCR.}

Streptomyces strains were grown to log phase (4 days) in shaken liquid media at $26^{\circ} \mathrm{C}$. Bacterial growth was halted using a stop solution (95:5 ethanol/acid phenol) at a 5:1 culture to stop solution ratio. Samples were mixed thoroughly and centrifuged, and the supernatant was decanted to recover mycelial pellets. RNA was extracted from the mycelium using RNeasy kit (cat. no. 74104) (Qiagen, Valencia, CA, U.S.A.) and was reverse transcribed using the SuperscriptIII first-stand synthesis system kit (Invitrogen, San Diego, CA, U.S.A.). Expression of the genes present in the fas locus was confirmed by amplifying the cDNA using gene-specific primers. The murX gene, involved in peptidoglycan biosynthesis, was used as a control in these analyses.

\section{Plant bioassays.}

For virulence assays, Arabidopsis thaliana (ecotype Columbia) and Nicotiana tabacum plants were produced in vitro from seed on Murashige and Skoog agar medium (MS) with $2 \%$ sucrose (Murashige and Skoog 1962) in Magenta boxes. Plants were grown at $21 \pm 2{ }^{\circ} \mathrm{C}$ with a 16-h day length and were inoculated with an $S$. turgidiscabies mycelium culture. Bacterial cultures were grown for 2 days in OBB prior to inoculation.

\section{Callus initiation.}

A. thaliana plants (ecotype Landsberg) and the cytokininsensitive mutants $c k h 1$ and $c k h 2$ (Kubo and Kakimoto 2000) were grown for 7 days on MS with $1 \%$ sucrose. Root segments were aseptically excised and placed on MS containing 2,4-D (200 mg/liter) and sucrose (2\%). This medium was supplemented with kinetin ( 25 or $100 \mathrm{mg} /$ liter) or $S$. turgidiscabies culture supernatant at $50 \mu \mathrm{l} / \mathrm{ml}$; cultures were grown in OBB medium for 4 days before the supernatant was harvested by centrifugation and filter sterilized. Plant tissue cultures were incubated for 21 days at $21 \pm 2{ }^{\circ} \mathrm{C}$ with a 16-h light and calli size and color were noted.

\section{ACKNOWLEDGMENTS}

This project was supported by the National Research Initiative of the United States Department of Agriculture Cooperative State Research, Education, and Extension Service, grant number 2005-35319-15289. We are grateful to T. Kakimoto for providing the Sln1 yeast mutant. We thank D. Vereeke for productive discussions.

\section{LITERATURE CITED}

Aloni, R., Aloni, E., Langhans, M., and Ullrich, C. I. 2006. Role of cytokinin and auxin in shaping root architecture: regulating vascular differentiation, lateral root initiation, root apical dominance and root gravitropism. Ann. Bot. 97:883-893.

Angra-Sharma, R., and Sharma, D. K. 1999. Cytokinins in pathogenesis and disease resistance of Pyrenophora teres-barley and Dreschslera maydis-maize interactions during early stages of infection. Mycopathologia 148:87-95.

Arkhipova, T. N., Veselov, S. U., Melentiev, A. I., Martynenko, E. V., and Kudoyarova, G. R. 2005. Ability of bacterium Bacillus subtilis to produce cytokinins and to influence the growth and endogenous hormone content of lettuce plants. Plant Soil 272:201-209.

Ausubel, F. M., Brent, R., Kingston, R. E., Moore, D. D., Seidman, J. G., Smith, J. A., and Struhl, K. 1998. Current Protocols in Molecular Biology. John Wiley and Sons, Hoboken, NJ, U.S.A. 
Bukhalid, R. A., Chung, S. Y., and Loria, R. 1998. nec1, a gene conferring a necrogenic phenotype, is conserved in plant-pathogenic Streptomyces spp., and linked to a transposase pseudogene. Mol. Plant-Microbe Interact. 11:960-967.

Carimi, F., Zottini, M., Formentin, E., Terzi, M., and Lo Schiavo, F. 2003. Cytokinins: new apoptotic inducers in plants. Planta 216:413-421.

Crespi, M., Vereecke, D., Temmerman, W., Van Montagu, M., and Desomer, J. 1994. The fas operon of Rhodococcus fascians encodes new genes required for efficient fasciation of host plants. J. Bacteriol. 176:2492-2501.

de O. Manes, C. L., Van Montagu, M., Prinsen, E., Goethals, K., and Holsters, M. 2001. De novo cortical cell division triggered by the phytopathogen Rhodococcus fascians in tobacco. Mol. Plant Microbe Interact. 14:189-195.

de O. Manes, C. L., Beeckman, T., Ritsema, T., Van Montagu, M. Goethals, K., and Holsters, M. 2004. Phenotypic alterations in Arabidopsis thaliana plants caused by Rhodococcus fascians infection. J. Plant Res. 117:139-145.

Eason, J. R., Morris, R. O., and Jameson, P. E. 1996. The relationship between virulence and cytokinin production by Rhodococcus fascians (Tilford 1936) Goodfellow 1984. Plant Pathol. 45:323-331.

Goethals, K., Vereecke, D., Jaziri, M., Van Montagu, M., and Holsters, M. 2001. Leafy gall formation by Rhodococcus fascians. Annu. Rev. Phytopathol. 39:27-52.

Goyer, C., Vachon, J., and Beaulieu, C. 1998. Pathogenicity of Streptomyces scabies mutants altered in thaxtomin A production. Phytopathology $88: 442-445$

Greenboim-Wainberg, Y., Maymon, I., Borochov, R., Alvarez, J., Olszewski, N., Ori, N., Eshed, Y., and Weiss, D. 2005. Cross talk between gibberellin and cytokinin: the Arabidopsis GA response inhibitor SPINDLY plays a positive role in cytokinin signaling. Plant Cell 17:92-102.

Haberer, G., and Kieber, J. J. 2002. Cytokinins. New insights into a classic phytohormone. Plant Physiol. 128:354-362.

Healy, F. G., and Lambert, D. H. 1991. Relationships among Streptomyces spp. causing potato scab. Int. J. Syst. Bacteriol. 41:479-482.

Healy, F. G., Bukhalid, R. A., and Loria, R. 1999. Characterization of an insertion sequence element associated with genetically diverse plant pathogenic Streptomyces spp. J. Bacteriol. 181:1562-1568.

Healy, F. G., Wach, M., Krasnoff, S. B., Gibson, D. M., and Loria, R. 2000. The $t x t A B$ genes of the plant pathogen Streptomyces acidiscabies encode a peptide synthetase required for phytotoxin thaxtomin A production and pathogenicity. Mol. Microbiol. 38:794-804.

Inoue, T., Higuchi, M., Hashimoto, Y., Seki, M., Kobayashi, M., Kato, T., Tabata, S., Shinozaki, K. and Kakimoto, T. 2001. Identification of CRE1 as a cytokinin receptor from Arabidopsis. Nature 409:1060-1063.

Jameson, P. E., Zhang, H., and Lewis, D. H. 2000. Cytokinins. Extraction, separation, and analysis. Methods Mol. Biol. 141:101-121.

Jeon, W. B., Allard, S. T., Bingman, C. A., Bitto, E., Han, B. W. Wesenberg, G. E., and Phillips, G. N., Jr. 2006. X-ray crystal structures of the conserved hypothetical proteins from Arabidopsis thaliana gene loci At5g11950 and AT2g37210. Proteins 65:1051-1054.

Kakimoto, T. 2001. Identification of plant cytokinin biosynthetic enzymes as dimethylallyl diphosphate:ATP/ADP isopentenyltransferases. Plant Cell Physiol. 42:677-685.

Kers, J. A., Wach, M. J., Krasnoff, S. B., Widom, J., Cameron, K. D., Bukhalid, R. A., Gibson, D. M., Crane, B. R., and Loria, R. 2004 Nitration of a peptide phytotoxin by bacterial nitric oxide synthase. Nature 429:79-82.

Kers, J. A., Cameron, K. D., Joshi, M. V., Bukhalid, R. A., Morello, J. E., Wach, M. J., Gibson, D. M., and Loria, R. 2005. A large, mobile pathogenicity island confers plant pathogenicity on Streptomyces species. Mol. Microbiol. 55:1025-1033.

Kieser, T., Bibb, M. J., Buttner, M. J., Chater, K. F., and Hopwood, D. A 2000. Practical Streptomyces Genetics. The John Innes Foundation Norwich, U.K.

King, R. R., Lawrence, C. H., Clark, M. C., and Calhoun, L. A. 1989. Isolation and characterization of phytotoxins associated with Streptomyces scabies. J. Chem. Soc. Chem. Commun. 13:849-850.

Kubo, M., and Kakimoto, T. 2000. The Cytokinin-hypersensitive genes of Arabidopsis negatively regulate the cytokinin-signaling pathway for cell division and chloroplast development. Plant J. 23:385-894.

Lambert, D. H., and Loria, R. 1989. Streptomyces scabies sp. nov., nom. rev. Int. J. Syst. Bacteriol. 39:387-392.

Lichter, A., Barash, I., Valinsky, L., and Manulis, S. 1995. The genes involved in cytokinin biosynthesis in Erwinia herbicola pv. gypsophilae: characterization and role in gall formation. J Bacteriol. 177:44574465

Loria, R., Bukhalid, R. A., Fry, B. A., and King, R. R. 1997. Plant pathogenicity in the genus Streptomyces. Plant Dis. 81:836-846.

Macdonald, E. M., Powell, G. K., Regier, D. A., Glass, N. L., Roberto, F., Kosuge, T., and Morris, R. O. 1986. Secretion of zeatin, ribosylzeatin, and ribosyl-1-methylzeatin by Pseudomonas savastanoi: plasmid-coded cytokinin biosynthesis. Plant Physiol. 82:742-747.

Maeda, T., Wurgler-Murphy, S. M., and Saito, H. 1994. A two-component system that regulates an osmosensing MAP kinase cascade in yeast. Nature 369:242-245

Maes, T., Vereecke, D., Ritsema, T., Cornelis, K., Thu, H. N., Van Montagu, M., Holsters, M., and Goethals, K. 2001. The att locus of Rhodococcus fascians strain D188 is essential for full virulence on tobacco through the production of an autoregulatory compound. Mol. Microbiol. 42:13-28.

Mahonen, A. P., Bishopp, A., Higuchi, M., Nieminen, K. M., Kinoshita K., Tormakangas, K., Ikeda, Y., Oka, A., Kakimoto, T., and Helariutta, Y. 2006. Cytokinin signaling and its inhibitor AHP6 regulate cell fate during vascular development. Science 311:94-98.

Manulis, S., Shafrir, H., Epstein, E., Lichter, A., and Barash, I. 1994. Biosynthesis of indole-3-acetic acid via the indole-3-acetamide pathway in Streptomyces spp. Microbiology 140:1045-1050.

Miyajima, K., Tanaka, F., Takeuchi, T., and Kuninaga, S. 1998. Streptomyces turgidiscabies sp. nov. Int. J. Syst. Bacteriol. 48:495-502.

Mumberg, D., Moller, R., and Funk, M. 1995. Yeast vectors for the controlled expression of heterologous proteins in different genetic backgrounds. Gene 156:119-122.

Murashige, T, and Skoog, F. 1962. A revised medium for rapid growth and bioassays with tobacco tissue cultures. Physiol. Plant. 15:473-497.

Pigac, J., and Schrempf, H. 1995. A simple and rapid method of transformation of Streptomyces rimosus R6 and other streptomycetes by electroporation. Appl. Environ. Microbiol. 61:352-356.

Rao, R. N., Richardson, M. A., and Kuhstoss, S. 1987. Cosmid shuttle vectors for cloning and analysis of Streptomyces DNA. Methods Enzymol. 153:166-198.

Sakakibara, H., Kasahara, H., Ueda, N., Kojima, M., Takei, K., Hishiyama, S., Asami, T., Okada, K., Kamiya, Y., Yamaya, T., and Yamaguchi, S. 2005. Agrobacterium tumefaciens increases cytokinin production in plastids by modifying the biosynthetic pathway in the host plant. Proc. Natl. Acad. Sci. U.S.A. 102:9972-9977.

Stevens, G. A., and Berry, A. M. 1988. Cytokinin secretion by Frankia sp. HFP ArI3 in defined medium. Plant Physiol. 87:15-16.

Takeuchi, T., Sawada, H., Tanaka, F., and Matsuda, I. 1996. Phylogenetic analysis of Streptomyces spp. causing potato scab based on 16S rRNA sequences. Int. J. Syst. Bacteriol. 46:476-479.

Taller, B. J., and Wong, T. Y. 1989. Cytokinins in Azotobacter vinelandi Culture medium. Appl. Environ. Microbiol. 55:266-267.

Temmerman, W., Vereecke, D., Dreesen, R., Van Montagu, M., Holsters, M., and Goethals, K. 2000. Leafy gall formation is controlled by fasR, an AraC-type regulatory gene in Rhodococcus fascians. J. Bacteriol. 182:5832-5840.

Vandeputte, O., Oden, S., Mol, A., Vereecke, D., Goethals, K., El Jaziri, M., and Prinsen, E. 2005. Biosynthesis of auxin by the gram-positive phytopathogen Rhodococcus fascians is controlled by compounds specific to infected plant tissues. Appl. Environ. Microbiol. 71:1169-1177.

Vereecke, D., Burssens, S., Simon-Mateo, C., Inze, D., Van Montagu, M., Goethals, K., and Jaziri, M. 2000. The Rhodococcus fascians-plant interaction: morphological traits and biotechnological applications. Planta 210:241-251.

Walters, D. R., and McRoberts, N. 2006. Plants and biotrophs: a pivotal role for cytokinins? Trends Plant Sci. 11:581-586.

Yang, Y.Y., Zhao, X. Q., Jin, Y. Y., Huh, J. H., Cheng, J. H., Singh, D., Kwon, H. J., and Suh, J. W. 2006. Novel function of cytokinin: signaling molecule for promotion of antibiotic production in streptomycetes. J. Microbiol. Biotechnol. 16:896-900.

Yoshida, M., and Kobayashi, K. 1991. Taxonomic characterization of the actinomycete causing root tumor of melon. Ann. Phytopathol. Soc. Jpn. 57:540-548. 